\title{
Genetic deletion of somatostatin receptor 1 alters somatostatinergic transmission in the mouse retina
}

\author{
Massimo Dal Monte a, Cristina Petrucci a, Anna Vasilaki ${ }^{\mathrm{b}}$, Davide Cervia ${ }^{\text {a }}$, \\ Dominique Grouselle ${ }^{\mathrm{c}}$, Jacques Epelbaum ${ }^{\mathrm{c}}$, Hans-Jurgen Kreienkamp ${ }^{\mathrm{d}}$, \\ Dietmar Richter ${ }^{\mathrm{d}}$, Daniel Hoyer ${ }^{\mathrm{b}}$, Paola Bagnoli ${ }^{\mathrm{a}, *}$ \\ a Dipartimento di Fisiologia e Biochimica, Università di Pisa, via San Zeno 31, 56127 Pisa, Italy \\ ${ }^{\mathrm{b}}$ Nervous System Research, Novartis Pharma AG, WSJ-386/745, 4002 Basel, Switzerland \\ c INSERUM, U-549, IFR Broca-Sainte Anne, Centre Paul Broca, 2ter rue d'Alesia, 75014 Paris, France \\ ' Institut für Zellbiochemie und Klinische Neurobiologie, Universitäts Kronkenhaus Eppendorf, 20246, Hamburg, Germany
}

Received 30 April 2003; received in revised form 8 July 2003; accepted 16 July 2003

\begin{abstract}
In the mammalian retina, sparse amacrine cells contain somatostatin-14 (SRIF) which acts at multiple levels of neuronal circuitry through distinct SRIF receptors $\left(\mathrm{sst}_{1-5}\right)$. Among them, the $\mathrm{sst}_{1}$ receptor has been localised to SRIF-containing amacrine cells in the rat and rabbit retina. Little is known about $s_{1} t_{1}$ receptor localisation and function in the mouse retina.

We have addressed this question in the retina of mice with deletion of $\mathrm{sst}_{1}$ receptors ( $\mathrm{sst}_{1} \mathrm{KO}$ mice). In the retina of wild type (WT) mice, $s s t_{1}$ receptors are localised to SRIF-containing amacrine cells, whereas in the retina of sst $_{1}$ KO mice, sst $_{1}$ receptors are absent. sst $_{1}$ receptor loss causes a significant increase in retinal levels of SRIF, whereas it does not affect SRIF messenger RNA indicating that $\mathrm{sst}_{1}$ receptors play a role in limiting retinal SRIF at the post-transcriptional level. As another consequence of sst ${ }_{1}$ receptor loss, levels of expression of $\mathrm{sst}_{2}$ receptors are significantly higher than in control retinas.

Together, these findings provide the first demonstration of prominent compensatory regulation in the mouse retina as a consequence of a distinct SRIF receptor deletion. The fact that in the absence of the $\mathrm{sst}_{1}$ receptor, retinal SRIF increases in concomitance with an increase in sst $_{2}$ receptors suggests that SRIF may regulate sst $_{2}$ receptor expression and that this regulatory process is controlled upstream by the sst $_{1}$ receptor. This finding can be important in the design of drugs affecting SRIF function, not only in the retina, but also elsewhere in the brain.
\end{abstract}

(C) 2003 Elsevier Ltd. All rights reserved.

Keywords: Somatostatin receptor 1 null mutation; Retinal cells; Somatostatin levels; Somatostatin receptor 2 expression; Compensatory events

\section{Introduction}

Somatostatin-14 (somatotropin release-inhibiting factor, SRIF) is a regulatory peptide produced throughout the central nervous system and in most major peripheral organs. It exerts its functions through the activation of distinct G-protein-coupled SRIF subtype receptors designated $\mathrm{sst}_{1-5}$ (Barnett, 2003, for review).

SRIF and its receptors are found in the retina. In particular, sparse-occurring SRIF-immunoreactive neurons

${ }^{*}$ Corresponding author. Tel.: +39-050-2213514; fax: +39-0502313527.

E-mail address: pbagnoli@dfb.unipi.it (P. Bagnoli). are present in the innermost inner nuclear layer (INL) and in the ganglion cell layer (GCL) of the mammalian retina (Bagnoli et al., 2003, for review). Those in the INL have been identified as amacrine cells, whereas those in the GCL are either displaced amacrine or ganglion cells. In the mouse retina, SRIF immunoreactivity (IR) has been recently localised to sparse-occurring amacrine cells present both in the proximal INL of the entire retina and in the GCL of the ventral retina (Cristiani et al., 2002).

In spite of the low density of SRIF-containing somata, dense SRIF-positive processes are widely distributed to distinct laminae of the inner plexiform layer (IPL) of the entire retina, thus suggesting that SRIF may act at multiple levels of retinal circuitry (Bagnoli et al., 2003, for 